\section{OPEN ACCESS}

Volume: 7

Issue: 2

Month: March

Year: 2019

ISSN: 2319-961X

Received: 3.3.2019

Accepted: 8.3.2019

Published: 15.3.2019

Citation:

Dhanya Shankar, k S.

"Practical Implications of Game Theory and Consumer Rights." Shanlax International Journal of Economics, vol. 7, no. 2, 2019, pp. 11-19.

DOI:

https://doi.org/10.34293/ economics.v7i2.307

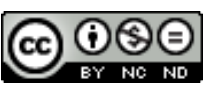

This work is licensed under a Creative Commons Attribution-NonCommercialNoDerivatives 4.0

International License

\title{
Practical Implications of Game Theory and Consumer Rights
}

\section{K.S.Dhanya Shankar}

Assistant Professor, Department of Economics St.Mary's College, Thrissur, Kerala, India

\begin{abstract}
Game theory is the formal study of conflict and cooperation. Game theoretic concepts apply whenever the actions of several agents are interdependent. These agents may be individuals, groups, firms, or any combination of these. The concepts of game theory provide a language to formulate structure, analyse, and understand strategic scenarios. Supermarkets are one such industry which is characterized by narrow profit margin and cut throat competition which had necessitated the need for the formulation and implementation of strategic decision. This interplay of decision making is similar to that of a game. This game of strategy can be used to test the real world theoretical implications of game theory. Thus from this context there arises the need of a study to test the game theory against the experimental evidences of real world economy and the analysis of the implications of game theory in experimental economics.
\end{abstract}

Keywords: Game, Players, Strategy, Nash Equilibrium, Payoff, Supermarket, Revenue, Expenditure, Profit

\section{Introduction}

Game theory is the science of strategy. It attempts to determine mathematically and logically the actions that "players" should take to secure the best outcomes for themselves in a wide array of "games." The games it studies range from chess to child rearing and from tennis to takeovers. But the games all share the common feature of interdependence. That is, the outcome for each participant depends on the choices (strategies) of all. Thus a game is any situation in which players make strategic decisions, the decision that take into account each other's actions and responses which results in payoffs to the players and these players always resort to an optimal strategy to maximize their expected payoff.

Nash equilibrium is a fundamental concept in the theory of games and the most widely used method of predicting the outcome of a strategic interaction in the social sciences. John Nash put some structure around how players in a "game" can optimize their outcomes. Nash Equilibrium is a term used in game theory to describe equilibrium where each player's strategy is optimal given the strategies of all other players. In other words, no player in the game would take a different action as long as every other player remains the same. Nash Equilibria are self-enforcing; when players are at a Nash Equilibrium they have no desire to move because they will be worse off. Nash equilibrium is useful not just when it is itself an accurate predictor of how people will behave in a game but also when it is not, because then it identifies situations in which there is a tension between individual incentives and other motivations. So it is clear that Nash equilibrium gives a valuable insight into the interdependence and strategic behaviour of economic agents. 


\section{Context of the study}

Game theory is concerned with how rational individuals make decisions when they are mutually interdependent. In many games the predictions of game theory are so specific and can be directly tested against real world evidences. So the study is concerned with testing whether the predictions of game theory are confirmed by individual's making interdependent actions in a controlled environment.

Consumer protection is a group of laws and organizations designed to ensure the rights of consumers as well as fair trade, competition and accurate information in themarketplace. The laws are designed to prevent businesses that engage in fraud or specified unfair practices from gaining an advantage over competitors. They may also provide additional protection for those most vulnerable in society. Consumer protection laws are a form of government regulation, which aim to protect the rights of consumers. For example, a government may require businesses to disclose detailed information about products - particularly in areas where safety or public health is an issue, such as food. Consumer protection is linked to the idea of consumer rights, and to the formation of consumer organizations, which help consumers make better choices in the marketplace and get help with consumer complaints.

Supermarkets are one such industry which is characterized by narrow profit margin and cut throat competition which had necessitated the need for the formulation and implementation of strategic decision. This interplay of decision making is similar to that of a game. This game of strategy can be used to test the real world theoretical implications of game theory. Thus from this context there arises the need of a study to test the game theory against the experimental evidences of real world economy and the analysis of the implications of game theory in experimental economics.

\section{Objectives}

- To evaluate the strategic decisions made by two players (supermarkets) in marketing of different products.

- To find out the outcome of marketing strategy of concerned players and effect on consumers satisfaction.
- To identify the factors influencing the profit and the factors responsible for Nash equilibrium position of the concerned players.

\section{Theoretical background of the study}

This segment deals with the theoretical foundation of the present study and different contributions in the field of game theory. The theoretical perspective developed in this study may be prefaced with a discussion of the existing concepts in game theory that have been evolved by academicians to explain the process of social choice. Game theory is the study of the ways in which interacting choices of economic agents produce outcomes with respect to the preferences (or utilities) of those agents, where the outcomes in question might have been intended by none of the agents.

\section{Evolution of Game Theory}

The earliest predecessors of game theory are economic analyses of imperfectly competitive markets. The pioneering analysers were those of the French economists AugustinCournot(1838) and the English economist Francis Edgeworth(1881) with subsequent advances due to Bertrand and Stackelberg). An early breakthrough in more modern times was the study of the game of Chess by Ernst Zermelo in 1913. The important works in modern times is a paper by John Von Neumann that was published in 1928 andthe subsequent book by him and Oscar Morgenstern titled Theory of Games and Economic behaviour (1944).

In their book Von Neumann and Morgenstern made three major contributions, in addition to formalizing the concept of a game. First, they gave an axiom- based foundation to utility theory, a theory that explains just what it is that players get from playing a game. Second, they thoroughly characterized the optimal solutions to what are called Zero-Sum Games, two-player games in which one player wins if and only if the other losses. Third, they introduced a version of game theory cooperative games. Although neither of these constructions is used very much in modern game theory, they both played an important role in the development of game theory that followed the publication of their book. 
The next great advance is due to John Nash who, in 1950, introduced the equilibrium concept which is the one most widely used in modern Game theory called, Nash equilibrium-has been extremely influential. Nash's approach advanced game theory from Zero-SUM to Non-Zero sum games (that is, situations in which both players could win or loss).

Reinhard Selten generalized the idea of Nash equilibrium to dynamic games, settings where play unfolds sequentially through time. In 1967-1968, John Harsanyi generalized Nash's ideas to settings in which players have incomplete information about each other's choices or preferences.

"Gaming" - playing game-theoretic problems for real- was common practice in the mathematical community at Princeton in the 1940s and 50s, and quickly spread elsewhere as game theory increased in popularity. This practice did not involve sophisticated experimental design, but was conceived mainly as a useful way of illustrating game theoretic puzzles, as well as a check on abstract speculation and guide to the theoretician's intuitions. Traces of this attitude can be found in the writings of some pioneers in game theory in the 1950s, who explicitly advocated a combination of formal theorizing with empirical evidence of various kind, and engaged in (mostly casual) forms of experimenting to back up their theoretical claims. A chapter of Thomas Schelling's The Strategy of Conflict (1960), for example, is revealingly called "Game Theory and Experimental Research"; and Martin Shubik's explorations of simulation and "gaming" in the same years also had a distinctively experimental flavor (Shubik, 1960).

Together with game theorists, experimenters have also been increasingly involved in policy making, notably by contributing to the design of new market institutions for the allocation of sensitive goods from telecommunication licenses to space stations, airport slots, and physicians and surgeons (Roth, 2002).

\section{Theoretical Aspects of Game Theory}

The object of study in game theory is the game, which is a formal model of an interactive situation. It typically involves several players; a game with only one player is usually called a decision problem. The formal definition lays out the players, their preferences, their information, and the strategic actions available to them, and how these influence the outcome.

Thus Game theory models seek to portray complex strategic situations in a highly simplified and stylized setting. Any situation in which individuals must make strategic choices and in which the final outcome will depend on what each person choose to do can be viewed as a Game. All games have three basic elements:

\section{Players}

Each decision maker in a game is called a player. These players can be individuals (as in poker games), firms (as in oligopoly markets) or entire nation (as in military conflicts). the number of players is fixed throughout the play of a game, and games are often characterized by the number of players (that is twoplayer, three-player or n-player).

\section{Payoffs}

The final returns to the players of a game as its conclusion are called payoffs. Payoffs are usually measured in levels of utility obtained by the players, although monetary payoffs (say, profits for firms) are often used instead.

\section{Strategy}

A strategy is a rule or plan of action for playing the game. Thus a game is any situations in which players make strategic decisions -i.e., decision that take into account each other's action and responses. A key objective of game theory is to determine the optimal strategy for each player. For price-setting firms, strategy might be: "I will keep my price high as long as competitors do the same, but once a competitor lowers his price, I will lower mine even more."

\section{Methodology of the study}

This study in is conducted to analyse the strategic decision undertaken by two players $\mathrm{A}$ and $\mathrm{B}$ (two supermarkets) in marketing their products and thereby increasing their profits. The two players have been selected from Thrissur district of Kerala state in random. The present study is mainly conducted through direct survey using structured questionnaire 
from both players and their 50 regular customers selected at random. The statistical tool of Factor Analysis has been employed for the present study. The collected data has been coded and analysed statistically and classified both qualitatively and quantitatively.

\section{Analysis of Collected Variables and Major Findings}

- This study had found that their strategic decisions relating to the general marketing, pattern of display, and promotional activities like advertisements confirms to the conditions of Nash equilibrium of game theory where each player is doing the best they can given what other players are doing. The special case of Nash equilibrium named as dominant strategy is reflected in the strategic decision of players related to pricing, sales and attracting customers. In these areas of strategic decisions, they are doing the best they can no matter what others are doing. Specifically, the areas of general marketing strategy where Nash equilibrium is reflected, in such a way that both players look up to each other's strategy but still they have formulated a unique strategy for themselves.

- $\quad$ Player A had a strategy of Maximum Material Availability at the same time Player B is following a strategy of Maximum customer Sovereignty.

- In the case of pattern of display, Player A follow a Brand Wise pattern of display where as Player B follow a gender based eye level pattern of display. But still both players regularly review the floor pattern of each other

- The special case of Nash equilibrium named as dominant strategy is reflected in the strategic decision of players related to pricing, where Player A had a strategy of 916 Rate and Player B had a strategy of C Mart rate.

- $\quad$ Player A has adopted the strategy of material wise product differentiation in the area of production and a relative cheaper price in the area of marketing. While Player B create its own branded products through the repacking technique.
Both players have distinctive location based demands and there by distinctive strategies. With response to increased demand of bakery and confectionary items from students of nearby area, Player A has introduced a new production unit exclusively for these items. While Player B satisfied the increased demand for consumer goods with premium quality products.

The advertising techniques and strategies of both players are more or less the same. Introduction of festival products, provision of discount coupons and banners are the most prominent strategies among them.

Both players have special allocations for advertising expenses. Player A usually allocate $5 \%$ to $7 \%$ of their margin for adds where as player B allocate only $3 \%$ to $5 \%$ of their margin for advertisements.

Both players had adopted the strategy of revision of market prices in every 15 days and they specially look up to the prices of other firms with in $5 \mathrm{~km}$ as a basis for changing prices. At the same time both of them have unique strategies in this respect. Player A had adopted the strategy of relative cheaper price where as player $\mathrm{B}$ tries to cover the cost of operation through the prices rather than maximizing profit. It reflects the Nash equilibrium.

Both players notice and adopt the marketing strategies of other profitable nearby supermarkets. Players mainly notice the strategy of other players for price comparison and to know about the availability of distinctive products.

Both players have agreed that they face acute completion from other players in terms of prices. Player A maximizes their profit and margin by compromising with their own unique strategies and benefits while player B had a strategy of adding core competency level to face the competition from other players.

- The major strategy of Player A in managing the unsold items is one that of making negotiations with the distributors in replacing 
the unsold items with moving items. Whereas that the strategy of Player B is one of introducing different offers on these kinds of products and try to sold out these at a reduced price.

- The sex wise distribution of customers in both supermarkets shows that the number of male customers in player $\mathrm{A}$ is similar to that of female customers in player B. Similarly number of male customers in player B is similar to that of female customers in player A.

- Both players have highest number of customers with the educational qualification of graduation and lowest number with secondary education.

- $\quad$ Player A's highest number of customers are from the public sector where as that of Player $\mathrm{B}$ are home makers.

- The highest number of customers in both supermarkets belongs to the income group of 40000-50000.

- $\quad 96 \%$ of customers from player A and $84 \%$ of customers from player B preferred supermarkets over other shopping stores due to the availability of all products at one place. While only a minimal of $4 \%$ from player A and $8 \%$ from player $\mathrm{B}$ choose price as the reason for their preference.

- $\quad 32 \%$ of customers have chosen Player A due to convenient distance and the highest number of customers who chose Player B is due to the quality of products.

- $\quad 56 \%$ from player A is weekly customers and player B have $32 \%$ of both weekly as well as monthly customers.

- The most preferred item of purchase of customers from Player A is vegetable, fruits and meat whereas that of player B is Grocery.

- The relationship between the strategies and outcome(consumers and producers) has been established in such a way that the most influential factor of the total individual satisfaction determine the strategic composition of each player.

- The total variance accounted by the extracted factors shows that $44.65 \%$ of variance in total individual satisfaction of customers from player A has been explained by the factor price. Similarly convenience and discount coupons explain $17.22 \%$ and $13.67 \%$ of variation in total individual satisfaction respectively.

- $35.52 \%$ of variance in total individual satisfaction of customers from player B has been explained by the factor of quality of product. Similarly convenience and provision of free offers explain $19.88 \%$ and $14.67 \%$ of variation in total individual satisfaction respectively.

\section{Statistical analysis of the variables}

The profitability of supermarkets in the game of marketing depends upon the success of the strategic decisions adopted by the players. These successes in turn depend upon the total satisfaction derived by the customers of that supermarket. Thus formulation and implementation of strategies for better profit and market share of players are based on this total individual satisfaction of the customers. So the most determining or influential factor of the total individual satisfaction determine the strategic composition of each player. These factors can be extracted using the statistical tool of Factor analysis.

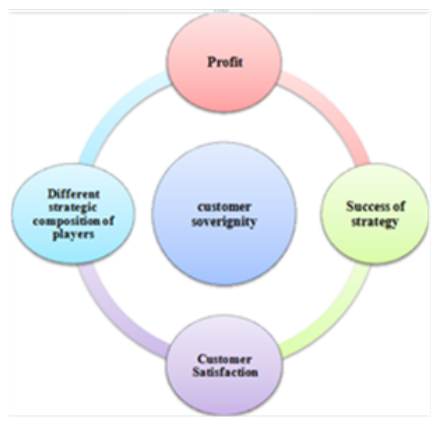

\section{Factor analysis of the Ranking of the strategic decision of Player A by Customers KMO and Bartlett's Test}

\begin{tabular}{|c|c|c|}
\hline \multicolumn{2}{|c|}{$\begin{array}{c}\text { Kaiser-Meyer-Olkin Measure of Sampling } \\
\text { Adequacy. }\end{array}$} & $\mathbf{. 6 3 2}$ \\
\hline \multirow{2}{*}{$\begin{array}{c}\text { Bartlett's Test of } \\
\text { Sphericity }\end{array}$} & Approx. Chi-Square & 149.533 \\
\cline { 2 - 3 } & $\mathrm{df}$ & 45 \\
\cline { 2 - 3 } & Sig. & .000 \\
\hline
\end{tabular}




\begin{tabular}{|l|c|c|c|}
\hline \multirow{4}{*}{ Rotated Component Matrix } \\
\cline { 2 - 4 } & \multicolumn{3}{|c|}{ Component } \\
\hline Price & $\mathbf{1}$ & $\mathbf{2}$ & $\mathbf{3}$ \\
\hline Pattern of display & .809 & .139 & -.143 \\
\hline Availability of products & .497 & .712 & .263 \\
\hline Quality of Products & .052 & .570 & .544 \\
\hline Convenience & .527 & .736 & -.021 \\
\hline Discount & -.128 & .906 & -.030 \\
\hline Special Offers & .817 & .226 & -.358 \\
\hline Free & .730 & .025 & .322 \\
\hline Festival offers & .809 & -.004 & .238 \\
\hline Discount coupons & .763 & .202 & .415 \\
\hline $\begin{array}{l}\text { Extraction Method: Principal Component Analysis. } \\
\text { Rotation Method: Varimax with Kaiser Normalization }\end{array}$ & .087 & .034 & .871 \\
\hline a. Rotation converged in 5 iterations. & & \\
\hline
\end{tabular}

In order to interpret the results of the above table, a cut-off point is decided. Now we use 0.8 as a cut-off point, three factors corresponding to factor 1 having a factor loading above 0.8 are price, discount and provision of free offers. The variable corresponding to factor 2 for which the factor loading are greater than 0.8 are convenience and the variable corresponding to factor 3 for which factor loading is greater than 0.8 are discount coupons.

Now factor 1 can be named as price related factors and the second factor is convenience and the third factor is discount coupons. Thus the most important factor determining the individual satisfaction of the customers of Player A are Price, Convenience and Discount Coupons.

Total Variance Explained

\begin{tabular}{|c|c|c|c|c|c|c|c|c|}
\hline \multirow{2}{*}{ Component } & \multicolumn{3}{|c|}{ Initial Eigen values } & \multicolumn{3}{c|}{$\begin{array}{c}\text { Extraction Sums of Squared } \\
\text { Loadings }\end{array}$} & \multicolumn{2}{c|}{$\begin{array}{c}\text { Rotation Sums of } \\
\text { Squared Loadings }\end{array}$} \\
\cline { 2 - 9 } & Total & $\begin{array}{c}\text { \% of } \\
\text { Variance }\end{array}$ & $\begin{array}{c}\text { Cumulative } \\
\text { \% }\end{array}$ & Total & $\begin{array}{c}\text { \% of } \\
\text { Variance }\end{array}$ & $\begin{array}{c}\text { Cumulative } \\
\text { \% }\end{array}$ & Total & $\begin{array}{c}\text { \% of } \\
\text { Variance }\end{array}$ \\
\hline 1 & 4.465 & 44.652 & 44.652 & 4.465 & 44.652 & 44.652 & 3.642 & 36.421 \\
\hline 2 & 1.722 & 17.219 & 61.871 & 1.722 & 17.219 & 61.871 & 2.306 & 23.063 \\
\hline 3 & 1.367 & 13.672 & 75.542 & 1.367 & 13.672 & 75.542 & 1.606 & 16.059 \\
\hline 4 & .800 & 7.997 & 83.539 & & & & & \\
\hline 5 & .690 & 6.896 & 90.435 & & & & & \\
\hline 6 & .421 & 4.208 & 94.643 & & & & & \\
\hline 7 & .235 & 2.355 & 96.998 & & & & & \\
\hline 8 & .130 & 1.303 & 98.301 & & & & & \\
\hline 9 & .096 & .956 & 99.257 & & & & & \\
\hline 10 & .074 & .743 & 100.000 & & & & & \\
\hline
\end{tabular}

The total variance accounted by the extracted factors shows that $44.65 \%$ of variance in total individual satisfaction has been explained by the factor price. Similarly convenience and discount coupons explain $17.22 \%$ and $13.67 \%$ of variation in total individual satisfaction respectively. 
Since this total individual satisfaction determines formulation of successful and distinctive strategies of a player in a game of maximizing profit and market share, we can say that profit maximizing strategy of player A mainly consist of these three strategies namely price, convenience and discount coupons.

The major strategy of player A in pricing consists of providing products at a 916 rate other than usual MRP rate. Under this rate each customer is able to avail a certain margin from their purchase. As far as the convenience factor is concerned it relates convenience of purchase which depends on the pattern of display. Player A has adopted a strategy of material wise product display for providing easy price comparison for the customers. The strategy of brand wise product display has also increased the convenience of shopping. The third factor determining the strategic composition of Player A is discount coupons. Player A has issued a Discount Coupon Card which is free of cost for the customers with unlimited warranty. The holders of this card are able to avail a $2 \%$ discount on their bill irrespective of their bill amount.

Thus the strategy of Player A can be expressed as a function these three factors as follows:

Where

$$
Y=\mathbf{f}(\mathbf{p}, \mathbf{c}, \mathbf{d})
$$

$\mathrm{Y}$ is the derived profit of the player

$\mathrm{p}$ is the price

$\mathrm{c}$ is the convenience

$\mathrm{d}$ is the discount coupons

Factor Analysis of the Ranking of the Strategic Decision of Player B

\begin{tabular}{|c|c|c|}
\hline \multicolumn{3}{|c|}{ KMO and Bartlett's Test } \\
\hline $\begin{array}{c}\text { Kaiser-Meyer-Olkin Measure of } \\
\text { Sampling Adequacy }\end{array}$ & $\mathbf{. 5 4 3}$ \\
\hline \multirow{3}{*}{$\begin{array}{c}\text { Bartlett's Test of } \\
\text { Sphericity }\end{array}$} & $\begin{array}{c}\text { Approx. } \\
\text { Chi-Square }\end{array}$ & 118.473 \\
\cline { 2 - 3 } & $\mathrm{df}$ & 45 \\
\cline { 2 - 3 } & Sig. & .000 \\
\hline
\end{tabular}

Rotated Component Matrix

\begin{tabular}{|l|c|c|c|}
\hline \multicolumn{1}{|c|}{ Component } & $\mathbf{1}$ & $\mathbf{2}$ & $\mathbf{3}$ \\
\hline Price & .046 & .749 & -.291 \\
\hline Pattern of display & .307 & .792 & .255 \\
\hline $\begin{array}{l}\text { Availability of } \\
\text { products }\end{array}$ & -.117 & -.686 & -.407 \\
\hline Quality of Products & .932 & -.017 & .201 \\
\hline Convenience & .024 & -.883 & -.124 \\
\hline Discount & .851 & -.025 & .357 \\
\hline Special Offers & .311 & .312 & .607 \\
\hline Festival Offers & .682 & .274 & -.256 \\
\hline Free & -.110 & .019 & .887 \\
\hline Discount coupons & .622 & .125 & -.087 \\
\hline Extraction Method: Principal Component Analysis. \\
\hline $\begin{array}{l}\text { RotationMethod: Varimax with Kaiser } \\
\text { Normalization. }\end{array}$ \\
\hline \multicolumn{4}{|l}{ a. Rotation converged in 5 iterations. } \\
\hline
\end{tabular}

In order to interpret the results of the above table, a cut-off point is decided. Now we use 0.8 as a cut-off point, three factors corresponding to factor 1 having a factor loading above 0.8 are quality of product and discount .The variable corresponding to factor 2 for which the factor loading is greater than 0.8 are convenience and the variable corresponding to factor 3 for which factor loading is greater than 0.8 is free.

Now factor 1 can be named as the factor of quality of product and the second factor is convenience and the third factor is provision of free offers. Thus the most important factor determining the individual satisfaction of the customers of Player B are Quality of product, Convenience and Provision of free offers. 


\begin{tabular}{|c|c|c|c|c|c|c|c|c|}
\hline \multirow{2}{*}{ Component } & \multicolumn{7}{|c|}{ Initial Eigenvalues } & \multicolumn{2}{c|}{$\begin{array}{c}\text { Extraction Sums of Squared } \\
\text { Loadings }\end{array}$} & $\begin{array}{c}\text { Rotation Sums of } \\
\text { Squared Loadings }\end{array}$ \\
\cline { 2 - 9 } & Total & $\begin{array}{c}\text { \% of } \\
\text { Variance }\end{array}$ & $\begin{array}{c}\text { Cumulative } \\
\text { \% }\end{array}$ & Total & $\begin{array}{c}\text { \%of } \\
\text { Variance }\end{array}$ & $\begin{array}{c}\text { Cumulative } \\
\%\end{array}$ & $\begin{array}{c}\text { Total } \\
\text { \% of } \\
\text { Variance }\end{array}$ \\
\hline 1 & 3.552 & 35.518 & 35.518 & 3.552 & 35.518 & 35.518 & 2.665 & 26.650 \\
\hline 2 & 1.988 & 19.880 & 55.398 & 1.988 & 19.880 & 55.398 & 2.627 & 26.273 \\
\hline 3 & 1.480 & 14.801 & 70.199 & 1.480 & 14.801 & 70.199 & 1.728 & 17.276 \\
\hline 4 & .945 & 9.448 & 79.647 & & & & & \\
\hline 5 & .637 & 6.365 & 86.012 & & & & & \\
\hline 6 & .513 & 5.134 & 91.146 & & & & & \\
\hline 7 & .338 & 3.379 & 94.525 & & & & & \\
\hline 8 & .291 & 2.906 & 97.431 & & & & & \\
\hline 9 & .220 & 2.204 & 99.636 & & & & & \\
\hline 10 & .036 & .364 & 100.000 & & & & & \\
\hline
\end{tabular}

The total variance accounted by the extracted factors shows that $35.52 \%$ of variance in total individual satisfaction has been explained by the factor of quality of product. Similarly convenience and provision of free offers explain $19.88 \%$ and $14.67 \%$ of variation in total individual satisfaction respectively.

Since this total individual satisfaction determines formulation of successful and distinctive strategies of a player in a game of maximizing profit and market share, we can say that profit maximizing strategy of player B mainly consist of these three strategies namely Quality of products, convenience and provision of free offers.

The major strategy of player B in ensuring quality of product is to collect the products directly from the producers without any intermediaries. Since this player is ranked as premium category supermarket most of the producers supply the products directly to the firm which increases the quality of products compared to other players in the market. As far as the convenience factor is concerned it relates convenience of purchase of products which depends on the pattern of display. Player A has adopted a strategy of gender based eye level display of products as a floor pattern. The products that are highly demanded by women are displayed according to their lower eye level and that of men are displayed in the higher level. Player A also charges a separate amount over branded products for providing major display space for branded products. So the major display will contain the branded products which gave a maximum margin to the player. The third factor determining the strategic composition of Player B is provision of free offers. Usually these offers are introduced as a strategy of selling out the surplus stock. These are sold out by introducing various offers both in terms of quantity and price. Thus this strategy is advantageous both for the customer and player.

Thus the strategy of Player B can be expressed as a function of these three factors as follows:

Where

$$
\mathrm{Y}=(\mathrm{q}, \mathrm{c}, \mathrm{f})
$$

$\mathrm{Y}$ is the derived profit of the player

$\mathrm{q}$ is the quality of products

$\mathrm{c}$ is the convenience

$\mathrm{d}$ is the discount coupons

$\mathrm{f}$ is the provision of free offers

- The increase in the rate of profit was higher for Player B than player A. So we can conclude that the strategic composition of Player B was better than that of Player A.

- $\quad$ Since both players are having a reasonable market share and profit both will be in the position of Nash equilibrium (No incentive to move from the current position). Thus the game of marketing reflects the features of Nash equilibrium.

\section{Conclusion}

It is clear from the analysis that both players 
follow their own unique strategies. The strategic composition of Player A consists of price, convenience and discount coupons where as that of Player B's consists of Quality of products, convenience and provision of free offers.

It is evident from the strategic composition of players that the strategies of both players confirm to the conditions of Nash equilibrium that both players are doing the best they can, given what others are doing. Both players are following their own unique strategies leading to normal profit showing the glimpses of Nash Equilibrium in the real world scenario.

\section{References}

Berninghaus, S.K. \& U. Schwalbe., "Evolution, interaction, and Nash equilibria," Journal of Economic Behavior and Organization, 57-85. 1996.

Brams, S.J., "Voting procedures, in: Aumann," R. J., S. Hart (eds.): Handbook of Game Theory, Vol. 2, Amsterdam: Elsevier Science, 10551089. 1994.

Brandenburger, A.L. \& B.J. Nalebuff., "The right game: Use game theory to shape strategy,"
Harvard Business Review, 57-71. 1995.

Camerer, C. \& K. Weigelt., "Experimental tests of a sequential equilibrium reputation model," Econometrica, 1-36. 1988.

Dixit, A. "Recent developments in oligopoly theory," American Economic Review, 12-17, 1982.

Ledyard, J.O. "Public Goods: A survey of experimental research, in: Kagel," J.H., A.E. Roth (eds.): The handbook of experimental economics, Princeton: Princeton University Press. 1995.

Samuelson, L. "Evolutionary games," New York: Wiley. 1997.

Selten, R. "Re-examination of the perfectness concept of equilibrium points in extensive games," International Journal of Game Theory, 4, 25-55, 1975.

Selten, R. "The chain store paradox, Theory and Decision," 9, 127-159, 1978.

Van Damme, E. "Stability and perfection of Nash equilibria, zweite, überar beitete und er weiterte Auflage," Berlin: Springer-Verlag. 1991.

\section{Author Details}

Dr.K.S.Dhanya Shankar, Assistant Professor, Department of Economics, St.Mary's College, Thrissur, Kerala, India Email ID:dhanya.shankar08@gmail.com 